\title{
Urban Water Balance 2. Results From a Suburb of Vancouver, British Columbia
}

\author{
C. S. B. Grimmond and T. R. OKe
}

\author{
Department of Geography, The University of British Columbia, Vancouver, British Columbia, Canada
}

\begin{abstract}
The paper demonstrates the use of the C. S. B. Grimmond et al. (this issue) water balance model. It is used to calculate the daily, monthly, and annual water balance components for a suburban catchment in Vancouver, British Columbia. The budget results for one complete year are presented and where possible are compared with those from other cities. The balance is also compared with that for a rural area in the region, thereby illustrating the effects of suburban development. In interpreting the results special consideration is directed toward elucidating the role of irrigation (mainly garden sprinkling) in the suburban water balance. The temporal pattern of external water use is related to prevailing weather conditions. In particular, it is shown to be closely related to evapotranspiration. The relationship is a complex feedback system involving human as well as biophysical controls. The model is run both with, and without, an irrigation input to gauge its impact on the water budget. Together the results provide both quantitative and qualitative support for the idea that irrigation is the source of water supporting the relatively large rates of suburban evapotranspiration reported in energy balance studies.
\end{abstract}

\section{INTRODUCTION}

This paper applies the urban water balance model of Grimmond et al [this issue] to a suburban catchment. The purpose of the study is to discover the daily, monthly, seasonal, and annual patterns of water exchange in an environment where human modification to hydrologic and climatologic processes, amongst others, is pronounced [Lazaro, 1979; Landsberg, 1981; Douglas, 1983].

These changes can be viewed in the simple unifying frameworks of the water and energy balances of urbanized terrain [e.g., Oke, 1978a]:

$$
\begin{gathered}
p+I=r+E+\Delta S \\
Q^{*}+Q_{F}=Q_{H}+Q_{E}+\Delta Q_{S}
\end{gathered}
$$

where $p$ is precipitation, $I$ is the piped-in water supply, $r$ is net runoff, $E$ is evapotranspiration, $\Delta S$ is net water storage change, $Q^{*}$ is net all-wave radiation, $Q_{F}$ is anthropogenic heat released by combustion, $Q_{H}$ and $Q_{E}$ are the turbulent heat fluxes of sensible and latent heat, respectively, and $\Delta Q_{S}$ is net heat storage change. The balances effectively share a common term, since $Q_{E}$ is the latent energy involved in the mass flux of water $E$. A priori it is usually suggested that urbanization leads to an increase in the water inputs $p$ and $I$ but a decrease in both $E$ and $\Delta S$ due to partial waterproofing and removal of vegetation. In response, urban runoff is usually greatly enhanced, leading to the need to engineer the orderly removal of large volumes of water following precipitation. The parallel view of urban effects on the energy balance holds that the urban inputs $Q^{*}$ and $Q_{F}$ combine to heat the city at least as strongly as its environs, and since the evapotranspiration output is likely to be reduced, the sensible heating of the air $Q_{H}$ and urban material $\Delta Q_{S}$ is boosted, giving the well-known heat island [Oke, 1982].

In this paper application of the Grimmond et al. [this issue] model helps elucidate the relative roles of the water balance

Copyright 1986 by the American Geophysical Union.

Paper number 5W4318.

$0043-1397 / 86 / 005 W-4318 \$ 05.00$ terms for a suburban area, the land use which occupies the largest fraction of the area of most cities. Special attention is given to the piped water supply for two reasons. First, residential domestic uses often account for more than half of total water use in many cities [Douglas, 1983]; therefore better knowledge of this term may be helpful in designing management strategies. Second, energy balance measurements in an area near the catchment used for this study suggest that evapotranspiration plays a more important role in (2) than might have been expected [Oke, 1978b, 1979; Kalanda et al., 1980; Oke and McCaughey, 1983] and that the piped supply, via garden irrigation, may also play an important part. Water balance data can help to establish if the reported energy exchanges are consistent with those of water.

\section{Methods}

\section{Sites and Instrumentation}

The Grimmond et al. [this issue] urban water balance model was applied to a residential suburb of Vancouver, British Columbia. The input data were derived from measurements conducted at three sites (Figure 1). The primary site, to which the model results apply, is the Oakridge catchment. This is a 21-ha test site set up by the City of Vancouver Engineering Department (Water Works Division). The catchment is defined by a linked network of water supply pipes. It is situated on a slight (less than $1^{\circ}$ ) southfacing slope. There are no streams flowing through the area, nor evidence that there were before urbanization [Proctor, 1978]. For budget purposes the catchment may be expected to exhibit no net long-term change in storage.

There are approximately 420 residents living in 191 one- or two-storey, single-family dwellings [Statistics Canada, Census Division, 1983]. Analysis of aerial photographs shows the catchment to have $60 \%$ pervious and $40 \%$ impervious land cover. Note that less than $1 \%$ of the surface cover was open water (swimming pools, etc.). Observations in the catchment included daily totals of water use by the households from a meter installed on the feeder pipe, and of precipitation based on the catches of four 100 -mm rain gauges mounted with their orifices $\mathbf{0 . 3} \mathrm{m}$ above the ground at different locations.

Soil moisture measurements were made once a week at a 


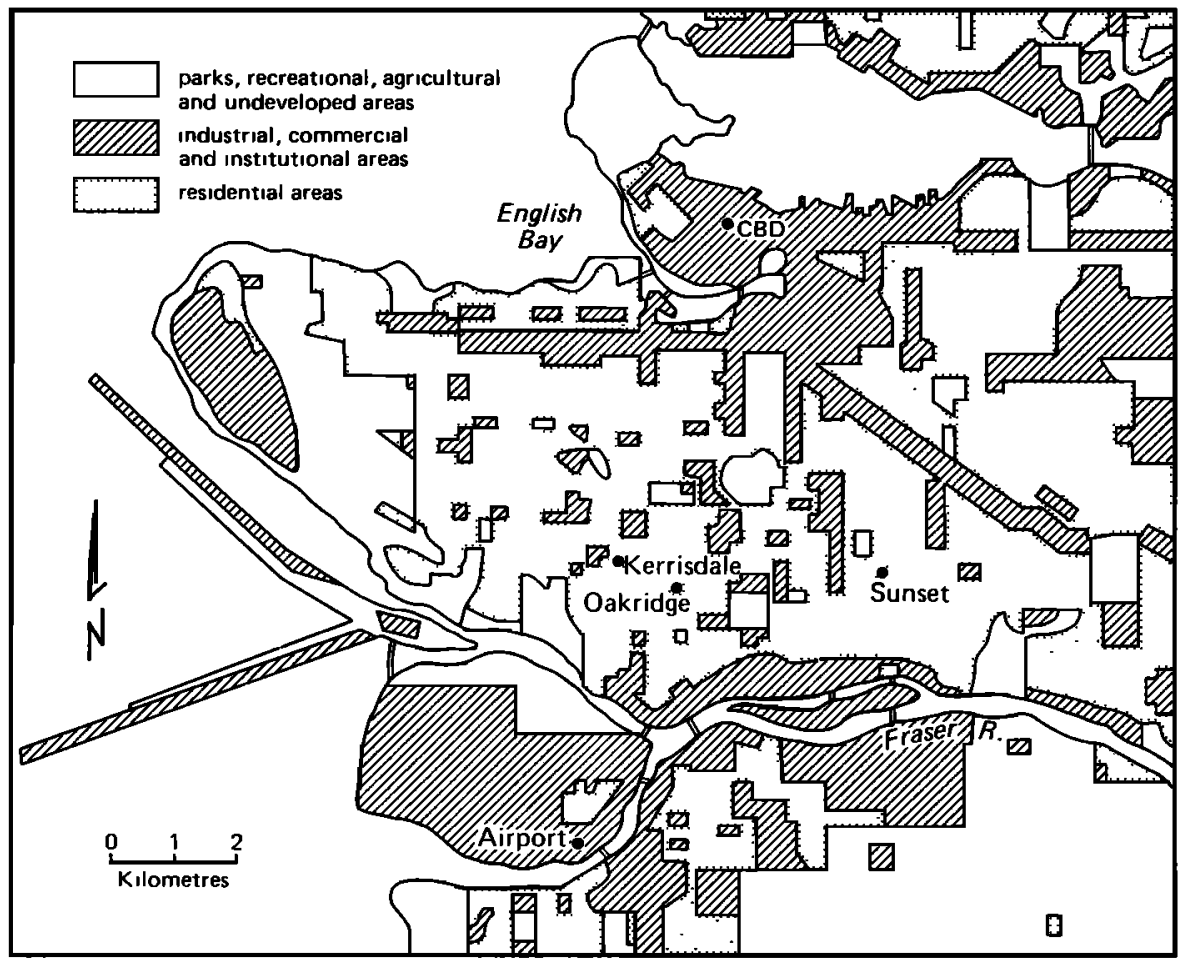

Fig. 1. Distribution of land uses in the Vancouver area and the location of the study catchment and climatological stations.

second site $0.3 \mathrm{~km}$ north of the Oakridge catchment (Figure 1). The average dry weight moisture content of the upper 0.2-m layer was determined using the gravimetric sampling technique [Gardner, 1965].

The third site, the Kerrisdale climate station, is $0.8 \mathrm{~km}$ northwest of the Oakridge catchment (Figure 1). A pneumatic, telescopic mast set up in a back garden supported instruments at a height of $9 \mathrm{~m}$ above the ground to sense net radiation (net pyrradiometer), wind speed (sensitive three cup anemometer), relative humidity (electrical capacitance), and air temperature (thermistor). Precipitation was monitored using a 200-mm diameter orifice tipping bucket rain gauge mounted on a garage roof at $5.7 \mathrm{~m}$. All signals were recorded hourly on a micrologger and stored on cassette tapes.

\section{Observation Period}

Observations were conducted at the three sites for one complete year: January 22,1982 , to January 21,1983 , inclusive; this will be referred to as the study year. It is perhaps helpful to consider how representative this year was in comparison with climatic normals. This can be accomplished with the aid of Table 1, which lists the mean monthly and annual climatic normals of five important meteorological variables for the Vancouver International Airport (Figure 1) together with the corresponding data for the study period.

Vancouver experiences a modified marine westcoast climate. Winters are mild, cloudy, and wet with frequent cyclonic activity. Summers are cool but sunny with moderate humidity. Thus for about half of the year input of water is high and radiant energy is low, whereas in the summer the reverse is true. Through much of the winter the soil storage is at field capacity or is saturated so that most of the abundant rainfall is lost as runoff, but in late summer it is common for there to be a water deficit and mild drought. (For details of the general energy and water balances of the Vancouver region see Hare and Thomas [1979].)

The footnotes to Table 1 draw attention to the most significant deviations of the study year from normal conditions. Considering the content of the present study the most important anomalies are that the May-June period was drier, July wetter and less sunny, and January 1983 much warmer, than normal. These features are only of interest in the context of representativeness of the study period. They present no special problems to the use of the model. During the study year virtually all of the precipitation fell as rain. No similar data exist to judge the normalcy of the water use and soil moisture data but no special conditions are to be anticipated.

The anthropogenic heat flux input to the urban system was not entered as a separate term. To do so would risk "double counting" this heat source because it is already represented in the measured net radiation, air temperature, and humidity data. General estimates for the total city of Vancouver have been given by $\operatorname{Yap}[1973]$ as 15,19 , and $23 \mathrm{~W} \mathrm{~m}^{-2}$ for the summer, winter, and annual periods, respectively.

The heat storage parameterization scheme used here is based on empirical relationships that strictly should only be used in the warmer half of the year. Their use in the winter leads to a nonzero storage over the annual period. To account for this the winter data were adjusted according to a simple linear correction scheme with a maximum correction of 18.6 $\mathrm{W} \mathrm{m}^{-2}$ on the date of the winter solstice.

\section{Model Input Values}

The values of the Oakridge catchment parameters used to run the Grimmond et al. [this issue] water balance model for the study period are listed in Table 2 . As noted, the areas of impervious and pervious land cover were determined from aerial photographs. It was assumed, based on general observa- 
TABLE 1. Comparison of Normal (1951-1980) and 1982-1983 Measured Values of Climatic Variables for Vancouver International Airport

\begin{tabular}{|c|c|c|c|c|c|c|c|c|c|c|}
\hline \multirow[b]{2}{*}{ Month } & \multicolumn{2}{|c|}{$\begin{array}{c}\text { Precipitation, } \\
\text { mm }\end{array}$} & \multicolumn{2}{|c|}{$\begin{array}{c}\text { Mean Air } \\
\text { Temperature, } \\
{ }^{\circ} \mathbf{C}_{-}\end{array}$} & \multicolumn{2}{|c|}{$\begin{array}{c}\text { Bright } \\
\text { Sunshine, } \\
\text { hours }\end{array}$} & \multicolumn{2}{|c|}{$\begin{array}{c}\text { Mean } \\
\text { Relative } \\
\text { Humidity, } \\
\%\end{array}$} & \multicolumn{2}{|c|}{$\begin{array}{l}\text { Mean Wind } \\
\text { Speed, } \\
\text { km h h}^{-1}\end{array}$} \\
\hline & Normal & 1982 & Normal & 1982 & Normal & 1982 & Normal & 1982 & Normal & 1982 \\
\hline January* & 153.8 & 238.6 & 2.5 & 1.9 & 53.5 & 23.6 & 87 & 85 & 12.2 & 12.4 \\
\hline Febru & 116.6 & 224 & 4.4 & 4.2 & 92.5 & 69.1 & 85 & 95 & 12.1 & 13.8 \\
\hline March & 101.0 & 64.9 & 5.8 & 5.5 & 129.3 & 151.9 & 82 & 78 & 13.5 & 11.4 \\
\hline April & 59.6 & 89.3 & 8.8 & 7.7 & 180.5 & 226.2 & 75 & 69 & 13.3 & 14.7 \\
\hline Maył & 51.6 & 22.6 & 12.2 & 12.1 & 246.1 & 251.5 & 74 & 70 & 11.8 & 12.2 \\
\hline June & 45.2 & 29.2 & 15.1 & 16.7 & 238.4 & 285.1 & 76 & 72 & 11.5 & 11.3 \\
\hline Julyब & 32.0 & 67.0 & 17.3 & 17.0 & 307.1 & 210.3 & 74 & 75 & 11.4 & 12.8 \\
\hline August & 41.1 & 37.2 & 17.1 & 16.8 & 256.2 & 219.9 & 78 & 77 & 10.6 & 12.3 \\
\hline September & 67.1 & 44.2 & 14.2 & 14.6 & 183.1 & 168.4 & 80 & 82 & 10.6 & 10.7 \\
\hline October & 114.0 & 118.0 & 10.0 & 10.2 & 121.0 & 126.7 & 87 & 83 & 11.2 & 12.9 \\
\hline November & 150.1 & 174.9 & 5.9 & 4.2 & 69.3 & 89.9 & 88 & 84 & 12.2 & 10.2 \\
\hline December§ & 182.4 & 149.7 & 3.9 & 4.1 & 47.9 & 71.8 & 89 & 83 & 13.0 & 12.2 \\
\hline Total & 1112.6 & 1260.2 & 9.8 & $\begin{array}{r}9.6 \\
1083\end{array}$ & 1919.6 & $\begin{array}{c}1894.4 \\
1983\end{array}$ & 82 & $\begin{array}{c}80 \\
1983\end{array}$ & 12.0 & $\begin{array}{l}12.2 \\
1983\end{array}$ \\
\hline January ${ }^{11}$ & 153.8 & $\begin{array}{l}1983 \\
172.3\end{array}$ & 2.5 & $\begin{array}{c}1983 \\
6.3\end{array}$ & 53.5 & 49.8 & 87 & $\begin{array}{l}1983 \\
86\end{array}$ & 12.2 & $\begin{array}{l}1983 \\
11.8\end{array}$ \\
\hline
\end{tabular}

Data from Environment Canada [1982; 1983] and Hay and Oke [1976].

* Sunshine second lowest on record.

tOne of the wettest.

$\ddagger$ Third driest on record.

TLowest sunshine and fifth wettest on record.

$\S$ Sunshine third highest.

"Warmest on record.

tion, that $50 \%$ of the pervious cover was in receipt of irrigation water. The values of the wind profile parameters (the displacement and roughness lengths) used were those calculated by Steyn [1980] for a similar residential area to the east of the Oakridge site (at sunset, see Figure 1). Estimates were based on a detailed description of the site geometry and the algorithms cited in the work by Grimmond et al. [this issue].

Values of the surface retention capacity were assigned following a review of the literature (Table 2) and weighted according to the fraction of the catchment area covered by the surfaces involved. The soil storage capacity was similarly chosen. Storage was assumed to be full at the initiation of the model; this is reasonable, since the model was initiated at the time of midwinter, a very wet period in Vancouver (Table 1). The soil field capacity was determined from field and laboratory tests. The infiltration rates for the pervious areas were assumed to be greater than the precipitation rates. This is based on measurements of infiltration rates (J. de Vries, personal communication, 1982; see Grimmond [1983]) and precipitation intensity records.

The mean daily winter water use $I_{w}$, which is used in the model to separate the internal from the external water supply $I_{e}$, was calculated to be the average of the metered data distributed across the total catchment area for the months November-March inclusive.

\section{Water Balance Results}

The Grimmond et al. [this issue] urban water balance model was run for the Oakridge catchment for the study year. The output gives the water balances of both the internal and external hydrologic systems (as defined in the work by Grimmond et al. [this issue] and illustrated in their Figure 1). These will be treated separately here; for water engineering and other purposes it would be acceptable to sum them to form one integrated suburban system.

\section{Internal System}

The internal balance simply consists of an equality between the input of piped water for domestic purposes within the home and the output of waste water via the sanitary drain and sewer system. At Oakridge the input was almost constant throughout the year. On a mean daily basis each household used $827 \mathrm{~L}$ of water, or about $376 \mathrm{~L}$ for each resident, which when averaged over the catchment is equivalent to a depth of $0.76 \mathrm{~mm}$ of water. The mean monthly quantities are therefore about $22 \mathrm{~mm}$. These figures do not account for water losses from the pipe system.

In relation to the total (internal plus external) runoff from the catchment, the output from the internal system is most important in the summer. At that time there is the least rainfall to shed, and the soil moisture storage is capable of accepting some infiltration. In fact, internal runoff $\left(r_{w} \simeq 22 \mathrm{~mm}\right)$ exceeded that in the external water budget $r_{e}$ for 4 of the summer months, and was of the same magnitude in 2 more (Figure 2). In winter the external runoff is almost an order of magnitude larger.

\section{External System}

The external suburban water balance for the study catchment is given as annual and seasonal totals in Table 3, and the monthly totals are plotted in Figure 2. This is the "peoplemodified" hydrologic system (including the effects of surface cover change such as removal of vegetation, paving over the soil, artificial drainage networks, etc.; the results of piped water use such as garden and other irrigation, filling swimming pools, street cleaning, storage ponds and reservoirs, etc., and any changes in precipitation climatology due to urban modification of the atmospheric boundary layer). Whereas the internal system is self-contained (except for leaks) and is routed by engineered pathways, the external system meshes 
TABLE 2. Values Used to Describe the Oakridge Catchment for 1982-1983 Water Balance Calculations

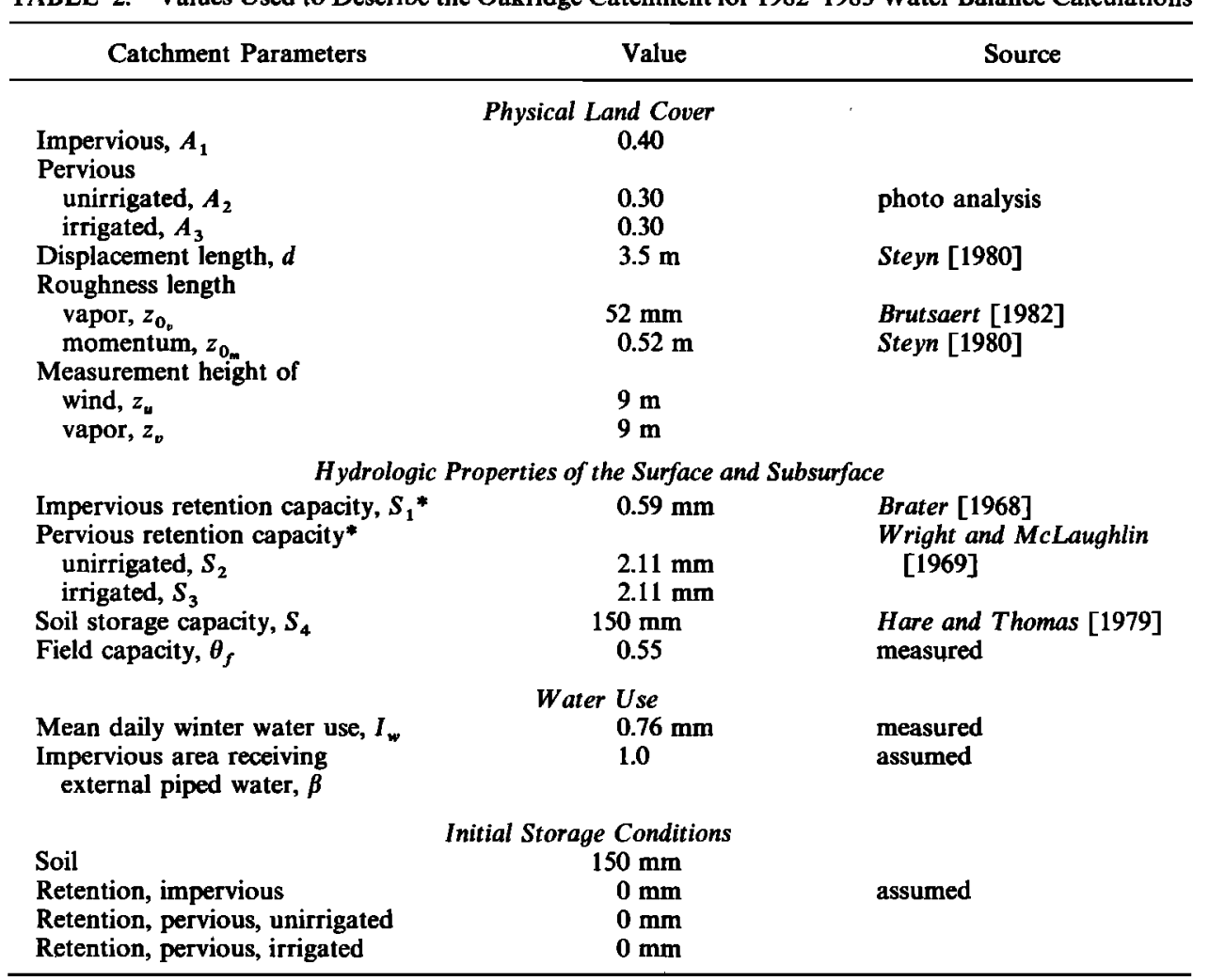

Calculations are determined using data from Grimmond [this issue].

*Capacity is the capacity for surface type $x$ fraction of area.

such networks with natural processes and environments to form a complex hydroclimatological feedback system.

Water inputs to the external system are strongly seasonal. In the winter, precipitation is the only significant input, but in summer external water use plays an equal role and in some months is the primary source. Thus summer irrigation belps to maintain the possibility of water availability in the Oakridge catchment throughout the year. How general this availability is depends on the spatial pattern of irrigation.

Outputs from the system show a similar seasonal bias. In the winter, when energy for evapotranspiration is limited and the soil moisture store is well stocked, $90 \%$ of the losses are as runoff. However, in the summer the primary output is to the atmosphere $(81 \%)$.

The change of soil (and other) moisture storage in the system is remarkably small. The system is between field capacity and saturation during the winter so there is little change. The greatest activity is in the spring when precipitation and runoff both drop but evapotranspiration is growing rapidly in response to increasing energy availability. Soils are still moist, vegetation has no difficulty in acquiring water for growth processes, and there is a significant draw down of the soil moisture store. By early summer the residents perceive a need to supplement the precipitation supply by irrigation. The linkage between this perception, the amount of water applied, and the status of the moisture store is close and will be dealt with in a later section. Figure 2 shows that the inputs are equal to, or slightly exceed, the outputs so that storage changes are small. By November the soil stores are restocked again.

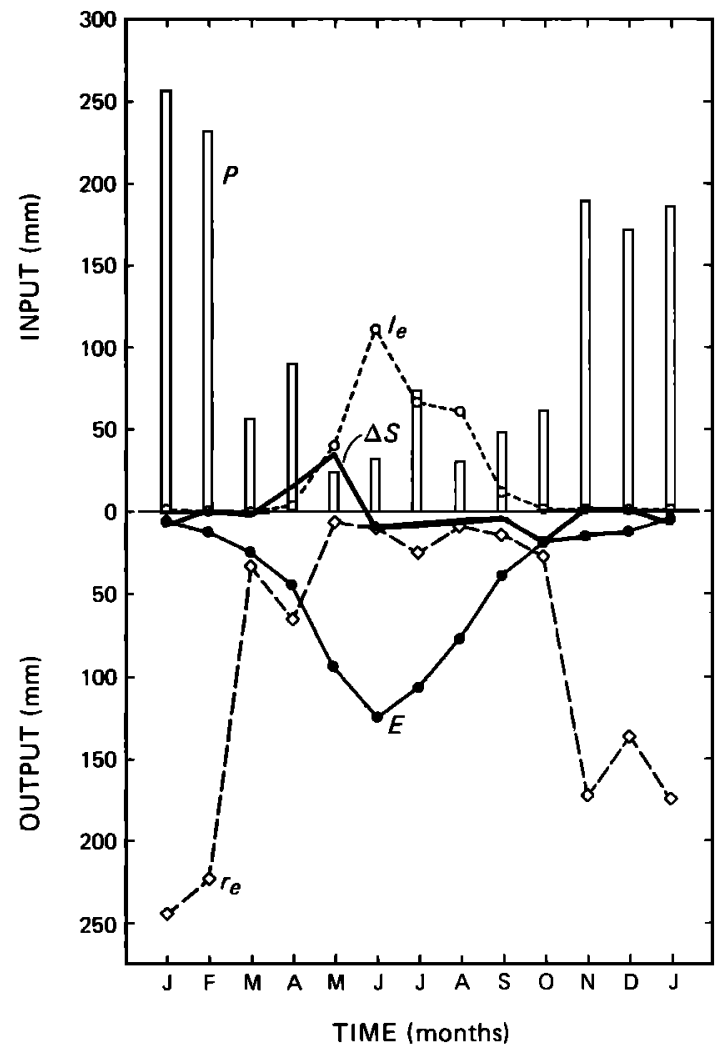

Fig. 2. External monthly water balance for the Oakridge suburban catchment for 1982 . 
TABLE 3. Seasonal and Annual Water Balances for the Oakridge Catchment

\begin{tabular}{crrrrrr}
\hline Period & \multicolumn{1}{c}{$p$} & + & \multicolumn{1}{c}{$I_{e}$} & $E$ & & \multicolumn{1}{c}{$\Delta S$} \\
\hline Summer & & & & & & \multicolumn{1}{c}{$r_{e}$} \\
mm & 298.0 & 296.2 & 483.0 & -18.1 & 129.2 \\
$\%$ & 50.1 & 49.9 & 81.3 & -3.0 & 21.7 \\
Winter & & & & & \\
mm & 916.7 & 5.5 & 94.6 & 21.5 & 806.1 \\
$\%$ & 99.4 & 0.6 & 10.3 & 2.3 & 87.4 \\
Year* & & & & & \\
mm & 1214.7 & 301.7 & 577.7 & 3.4 & 935.4 \\
$\%$ & 80.1 & 19.9 & 38.1 & 0.2 & 61.7 \\
\hline
\end{tabular}

Results are for the external water system only and are expressed both as depth of water $(\mathrm{mm})$ and as percentage of the total water input (\%).

*The study year. See Table 4 for the corresponding whole system (internal and external) annual water balance.

\section{Comparison With Other Urban Balances}

Table 4 is a summary list of attempts to evaluate the water balance of cities or urbanized catchments. Direct comparison of the results from these studies is not straightforward for many reasons. Foremost amongst which are the geographic differences between cities (e.g., climate, physiography, vegetation, soils, urban form and urban function, especially degree of industrialization), the definition of the area represented (e.g., whole or part of a city or an amalgam of urbanized territories such as in the case of Sweden, Table 4), and not least the emphasis of the original study and the techniques used to estimate or measure the terms in the balance. In constructing Table 4 some license has been taken in interpreting the original studies and, in order to aid comparison, the balances have been standardized to a whole (external and internal) basis and to the annual period.

It is evident that the piped water supply represents from 14 to $40 \%$ of the total water input of these cities and that the Oakridge values are close to average. The piped input can be partitioned between domestic, industrial, municipal, and agricultural uses, plus leakage. In many urban areas domestic use is the largest category (e.g., Sydney $59 \%$, Sweden $55 \%$, and Mexico City 53\%). In old water distribution systems, especially where frost heave is a problem, leakage "losses" from the water mains may approach $50 \%$ [Douglas, 1983].

On an anual basis change in storage is approximately zero so the output side of the budget is shared by evapotranspiration and runoff. The exact breakdown depends on many factors including the degree of surface waterproofing by built uses, the natural and engineered drainage net, irrigation practices, general climate, etc. The range in Table 4 shows each of these terms can account for $30-70 \%$ of the output. Perhaps the least expected result for most hydrologists is to find that evapotranspiration from mid- and high-latitude cities can approach $60 \%$ on an annual basis, and as demonstrated earlier, can be greater than $\mathbf{8 0} \%$ in the summer months for the external budget.

The external budget results for Oakridge compare very favorably with the results of an analysis conducted by $\mathbf{S}$. $\mathbf{M}$. Loudon and T. R. Oke (unpublished manuscript, 1986) in the same Oakridge catchment for two summer months in 1980 (Table 5). The 1980 study utilized a very much simpler computational scheme. The proportion of the water input derived from piped water was the same in both years, as was that contributing to runoff. The primary difference is the role of evapotranspiration. In 1980 an amount equivalent to all the input $\left(p+I_{e}\right)$ was lost to the air leading to a draw down of the soil moisture store. The extreme conditions underlying the 1980 results have been discussed by Oke and McCaughey [1983] and Cleugh and Oke [1986].

\section{Suburban-Rural Hydroclimatological Parameters}

Hare and Thomas [1979] provide water balance data for the Vancouver area using Thornthwaite climatological budget techniques and the Vancouver Airport climatological normals. Here we will characterize these estimates as being for a "rural" site and will compare them with the 1982 suburban set. To minimize some of the problems associated with comparing normals versus a single year, and a natural budget versus one supplemented by irrigation, the data have been nondimensionalized by expressing all values as ratios of the total water input to the system. For example, the rural-runoff ratio is defined as is usual:

$$
C_{r}=r_{r} / p_{r}
$$

but the corresponding suburban ratio is

$$
C_{s}=r_{s} /\left(p+I_{e}\right)
$$

Similar ratios are defined for evapotranspiration $F$ and water storage change $G$ for both environments. Finally, to illustrate the degree to which the suburban balance is supplemented by irrigation we have an irrigation ratio $\left(H_{s}=I_{e} /\left(p+I_{e}\right)\right)$.

In most respects both environments behave in a similar fashion during the precipitation-dominated, colder half of the year (Figure 3). In the other half very marked rural-suburban differences occur, especially in $F$ and $G$. This is coincident with the period of irrigation when $H_{S}=0.78$ (June) there is 3.5 times more water input to the suburban system than without irrigation.

The rural and suburban ratios show a similar variation through the year (Figure 3a). Overall, the suburban environment sheds a greater proportion of its input via runoff. On an annual basis, $C_{r}=0.5$ and $C_{S}=0.62$. This is probably attributable to the greater waterproofing of the suburban surface and to the summer stocking of soil moisture by irrigation. The latter factor reduces the need to recharge soil moisture in the autumn and hastens the arrival of the time when input generates runoff. Figure $3 a$ also includes measured data from a rural catchment east of Vancouver. The ratios were computed using the gauged streamflow from West Creek (44 km to the west of the study site) and precipitation from the Whalley Forest Nursery climate station ( $22 \mathrm{~km}$ to the west of the study site). In general, the agreement is reasonable but the higher summer values at West Creek are probably due to groundwater affecting the baseflow. Groundwater was not considered to be important in the calculations for the other two cases.

The summer evaporation and storage change ratios (Figure $3 b$ ) are very interesting. The rural pattern shows evapotranspiration to greatly exceed the water input (i.e., $F_{r}>1$ ) from May to September. This results in a dramatic drop in water storage for the same period. The suburban case begins the same way in May but thereafter shifts to a quite different mode: from June to September evapotranspiration stays smaller than the water supply $\left(F_{S}<1\right)$. Indeed, $F_{S}$ almost seems to be tied to $H_{S}$, raising the possibility that irrigation plays a controlling role in suburban evapotranspiration. Equally remarkable is the lack of storage change during the summer. Since $C_{S}$ is not a major component at this time, this implies some degree of off-setting, feedback, or balance between $F_{S}$ and $H_{S}$. These questions are the focus of the section which follows. 
TABLE 4. Examples of Urban Water Balance Studies (in Order of Decreasing Area)

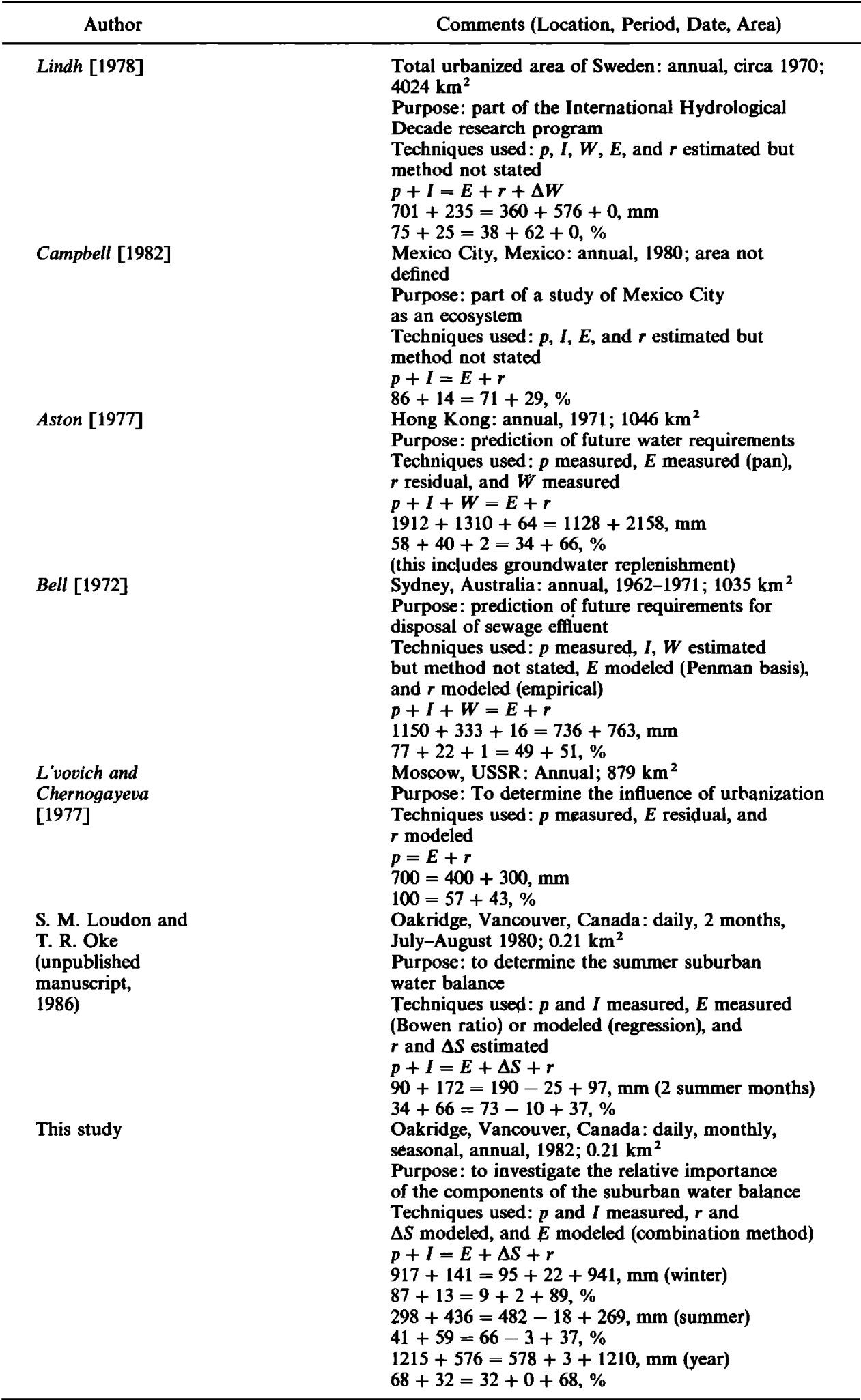

Here, $W$, groundwater; $\Delta W$, change of groundwater storage.

\section{Role of SUburban IrRIgation}

\section{Suburban Irrigation Patterns}

The Oakridge residential area is generally a prosperous one with larger than average lots $\left(670 \mathrm{~m}^{2}\right)$ that are generally as- sociated with well-tended gardens. The water supply is based on a flat rate of payment and use is unrestricted. On an annual basis, $52 \%$ of the piped water is used for garden sprinkling.

Two water use patterns are evident at Oakridge. First, in 
TABLE 5. Comparison of the Oakridge External Water Budget in July-August 1982 With That in 1980 for the Same Months

\begin{tabular}{|c|c|c|c|c|c|c|c|c|c|}
\hline Year & $p$ & + & $I_{e}$ & $=$ & $E$ & + & $\Delta S$ & + & $r$ \\
\hline \multicolumn{10}{|l|}{1982} \\
\hline $\mathrm{mm}$ & 103 & + & 128 & $=$ & 182 & + & 16 & + & 33 \\
\hline$\%$ & 45 & + & 55 & $=$ & 79 & + & 7 & + & 14 \\
\hline \multicolumn{10}{|l|}{1980} \\
\hline $\mathrm{mm}$ & 90 & + & 106 & $=$ & 190 & - & 25 & + & 31 \\
\hline$\%$ & 46 & + & 54 & $=$ & 97 & - & 13 & + & 16 \\
\hline
\end{tabular}

After S. M. Loudon and T. R. Oke (unpublished manuscript, 1986).

the colder half of the year (e.g., Figure 4 (top)) the total water use $I=I_{w}$ is almost constant at approximately $0.76 \mathrm{~mm} \mathrm{~d}^{-1}$ and shows no dependence upon weather characteristics. Second, in the warmer half of the year (Figure 4 (bottom)) the amounts are often greater (up to a maximum of $7.7 \mathrm{~mm} \mathrm{~d}^{-1}$, of which approximately $7 \mathrm{~mm} \mathrm{~d} \mathrm{~d}^{-1}$ is attributable to external uses) and the pattern is very much more variable. Even visually it is evident that variability is related to weather events.
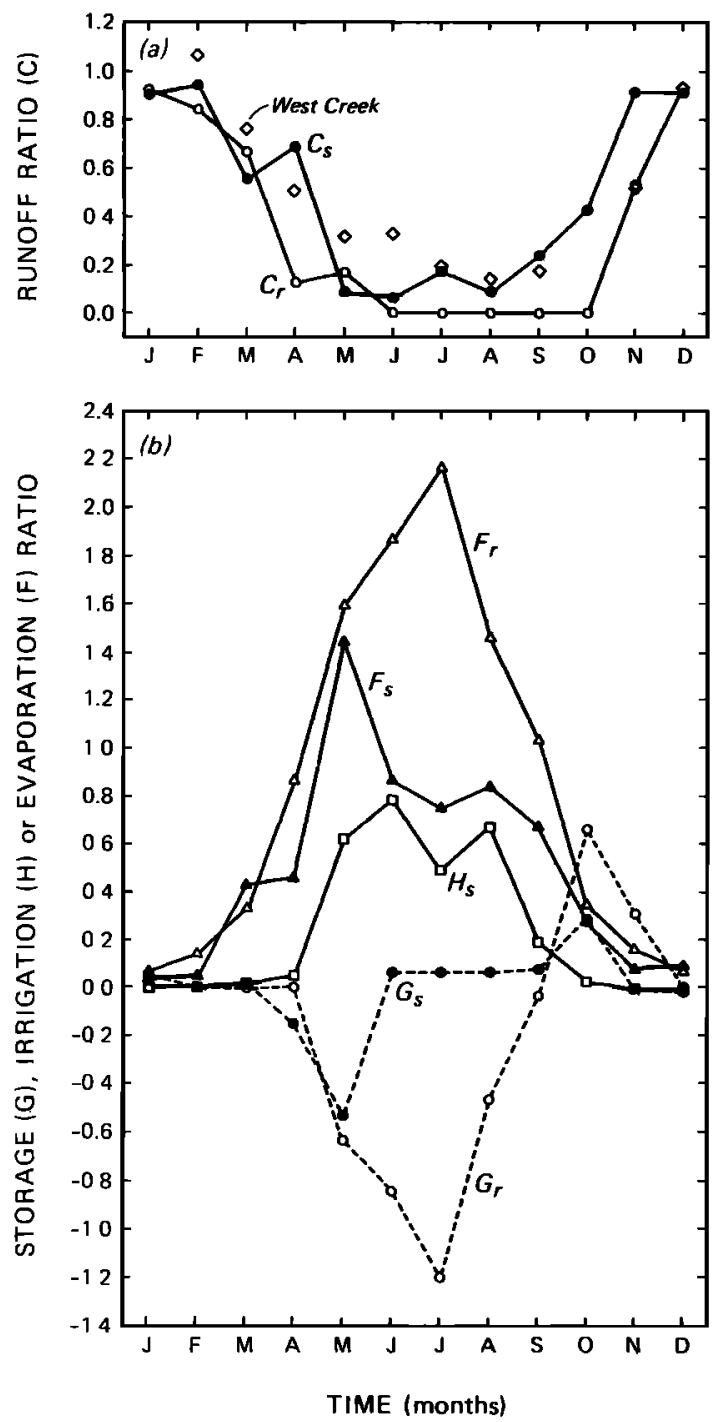

Fig. 3. Annual variation of hydroclimatological parameters for rural (Vancouver Airport) and suburban (Oakridge) environments, where $C$ is the runoff ratio, $F$ is the evapotranspiration ratio, $G$ is the water storage change ratio, $H$ is the irrigation ratio, subscript $s$ is suburban, and subscript $r$ is rural. See text for definition of ratios and data sources.
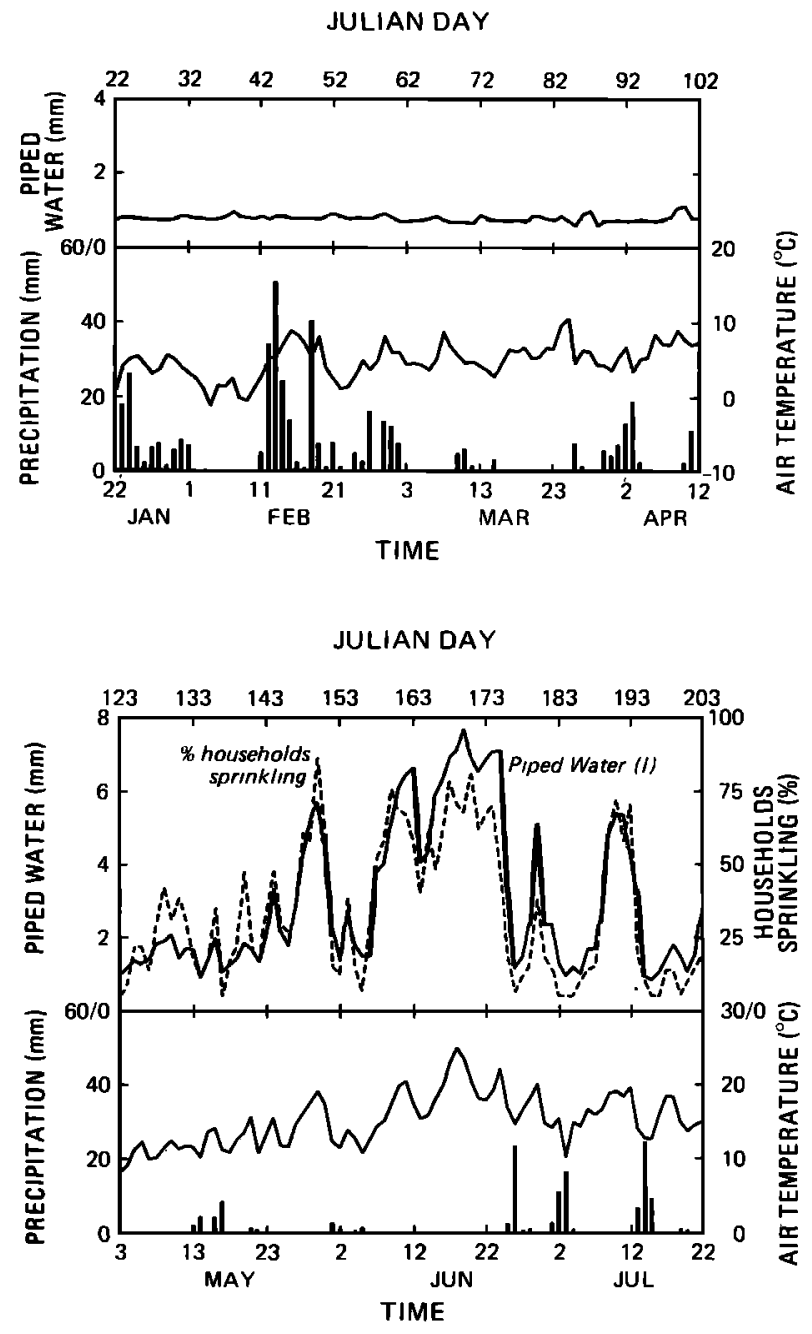

Fig. 4. Variation of daily totals and averages of total water use $I$ and climatological characteristics at Oakridge in the periods January-March 1982 (top) and May-July 1982 (bottom).

Precipitation leads to a drop in external use; on the other hand, increases of air temperature or solar radiation (not shown) give rise to an increase in water use (for sprinkling, swimming pools, car washing, etc.).

The importance of sprinkler irrigation was confirmed through a survey of Oakridge residents in May-August 1982. During this period approximately $12 \%$ of the households maintained a daily diary of water use activities. The percentage of survey households reporting external use on each day are plotted in Figure 4 (bottom), and show a remarkable correspondence with the piped water record from the meter. It shows that suburban water use variations are the result of more or less people watering rather than the same number using greater or lesser amounts of water. Sprinkling was the overwhelmingly reported use.

The association between summer water use and weather can be quantified statistically. Simple linear regression between $I$ and air temperature alone explains $66 \%$ of the variance and for the July-August period this rises to $72 \%$. S. M. Loudon and T. R. Oke (unpublished manuscript, 1986) found a $66 \%$ explanation for the same variable in July-August of 1980 . Cohen [1985] found similar results for Metropolitan Toronto during the summer. If additional variables such as the number 
JULIAN DAY

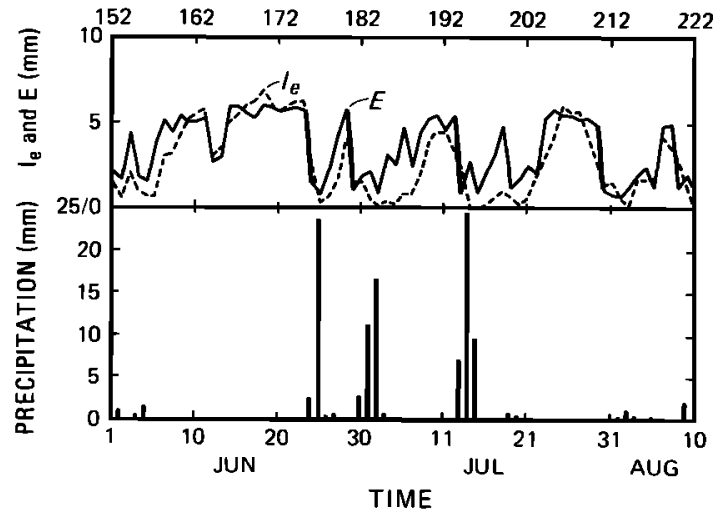

Fig. 5. Daily totals of external water use $I_{e}$ and evapotranspiration $E$ at Oakridge during a midsummer period of 1982.

of days since precipitation, soil moisture and net radiation are included in a stepwise multiple regression analysis the explanation of variation can be raised to $85 \%$. This high level of explanation is possible despite the influence of nonweather factors (e.g., day of week, holidays) and is thus interesting because the processes involved are not simply part of a physical cause-and-effect system. The sequence involves human decision making and action (to sprinkle or not) which is only indirectly linked to weather events through the perception and assessment of the need for water.

\section{Suburban Irrigation and Evapotranspiration}

As was noted in the introduction, energy balance studies at the Sunset site (Figure 1) have raised basic questions concerning relatively large rates of evapotranspiration from suburban areas. Four of the most important queries are as follows.

1. Are the latent heat flux measurements, via Bowen ratioenergy balance and eddy correlation-energy balance techniques, consistent with the availability of water?

2. Could irrigation sprinkling be the source of the water?

3. Are the temporal patterns of irrigation and evapotranspiration linked in such a way as to explain the observed "rebound" of $E$ during a period with no precipitation? The rebound referred to follows a sequence: precipitation causes an increase in the role of latent heat in the energy balance (the Bowen ratio decreases), over the next few days apparent drying out causes a steady decline in the role, but this is followed by an unexpected recovery.

4. What processes are capable of maintaining relatively large evapotranspiration rates in a suburban area? Despite the surface at Sunset being $36 \%$ impervious, and probably half of the remaining area receiving no irrigation, observations show evapotranspiration proceeding at close to the equilibrium rate with Bowen ratios usually less than 2 , and typically around unity, even many days after precipitation.

A number of answers to these questions are provided or are implied by the contents of Figure 5. It includes the daily totals of external water use $I_{e}$ and evapotranspiration $E$ from the Oakridge site during a period in the summer. Given the agreement between the two traces it is worth reiterating that they are obtained completely independently, $I_{e}$ comes from the metered water supply data (after subtraction of $I_{w}$ ) and is governed by human decisions regarding the need for water. $E$ is calculated from climatological station data using the Grimmond et al. [this issue] evapotranspiration submodel and is controlled by a variety of biological, hydrological, and climatological processes. A similarly striking relationship was obtained by S. M. Loudon and T. R. Oke (unpublished manuscript, 1986) for the same site in 1980 and included measured $E$ from energy balance observations.

The magnitude of most of the maximum $I_{e}$ and $E$ values are in the range $5-6 \mathrm{~mm} \mathrm{~d}^{-1}$ during this midsummer period. Why they should agree so well is not clear. It may be purely fortuitous, or it is conceivable that irrigation topping up of the soil moisture is maintained at just the rate necessary to match the losses thereby keeping $\Delta S$ approximately zero. However, such action would also have to take into account the contribution to storage by precipitation. There is some evidence of this. Notice that whereas the irrigation response to precipitation input is virtually immediate, the recovery following the event reveals an inertia compared to the evapotranspiration (e.g., July 4-10, July 15-18). By contrast the recovery following a cloudy (but not rainy) period is more immediate (e..g, June 15, August 6). This suggests that the perception of soil moisture status (probably to support a green lawn) is the motivating factor. Woolmington and Burgess [1983] also consider that watering is strongly related to the perception of heat and the consequent desire to engage in water play. They also note that much of the irrigation in Canberra is careless, leading to runoff, as water finds its way onto footpaths, driveways, and road gutters, and then to streams or sewers. A similar observation applied to the Oakridge catchment.

The system illustrated in Figure 5 is probably a complex feedback loop so that it is difficult to identify the driving force. Certainly, the removal of water by evapotranspiration creates the requirement for irrigation, but as a consequence, evapotranspiration is enhanced due to the greater availability of water. Nevertheless, the closeness of the linkage revealed by Figure 5, and the corresponding one of S. M. Loudon and T. R. Oke (unpublished manuscript, 1986) is unexpected.

The availability of the Grimmond et al. [this issue] model makes it possible to simulate the effect of irrigation upon the suburban water balance. Figure 6 shows the difference between the monthly external budget components for Oakridge in 1982 when $I_{e}$ is excluded. All other inputs remain the same as before. During the summer irrigation season evapotranspiration losses are considerably reduced. Summed over the

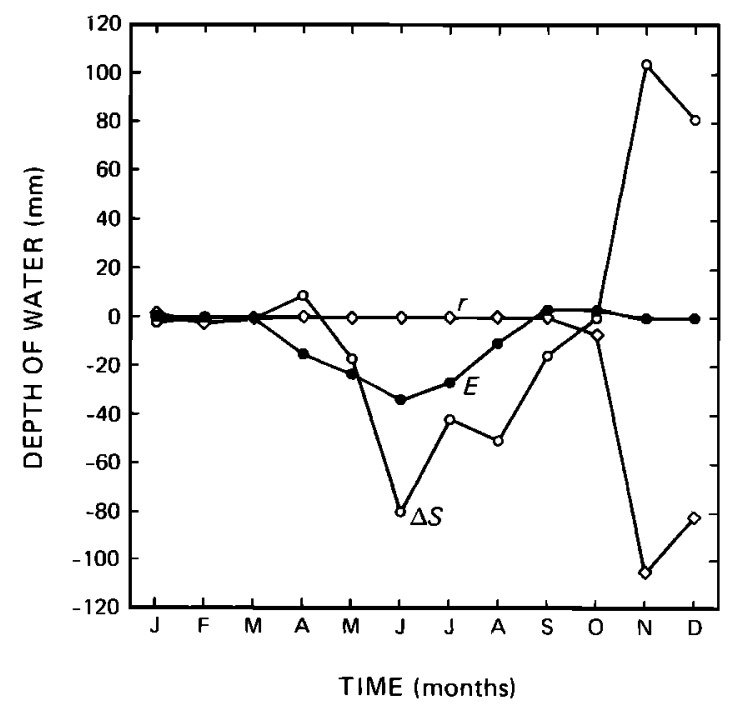

Fig. 6. Differences in monthly external water budget totals due to the exclusion of irrigation. 
period April-August $E$ is decreased by $24 \%$ if no irrigation is applied. It can be noted that the biggest impact on the summer balance would be to create a soil water deficit (despite lowered $E$ ) because of the reduced ability to restock. Even greater delayed effects occur in the October-December period. When precipitation inputs start to dominate, the irrigation case generates much less runoff because a much larger proportion of the input is used to stock the soil moisture store. The corollary of this is that irrigation may lead to increased risk of suburban storm flooding in the autumn. This is an example of where the proposed model would be a useful part of stormwater modeling.

Returning to the questions posed at the start of this section, the present study enables us to make the following conclusions.

1. Based on the external balance data in Figures 2 and 5 there seems no doubt that there is sufficient water available in the suburban environment to support the energy balance estimates of evapotranspiration.

2. The same data clearly support the possibility that irrigation is the source of the water.

3. The temporal patterns of $I_{e}$ and $E$ (Figure 5) appear to be strongly connected. Following precipitation there is a delayed recovery of the $I_{e}$ term during which period drying out starts to occur, and $E$ may decrease in importance in the energy balance. After about 4-6 days $I_{e}$ recovers to approximately match $E$, and the rebound of $E$ is possible. Indeed, the largest daily total $E$ value was registered 11 days after the last rainfall (see June 16, Figure 5), and high values continued for up to 19 days after rain in the same sequence.

4. Although the preceding considerations show enough water is available from sprinkling to support the relatively high rates of evapotranspiration observed, appropriate processes are needed to explain how a patchy, wet-dry surface achieves the end result. We suggest that two scales of advective effect may be involved. The first is the microscale process of "oasis"-type advection demonstrated by Oke [1979] for an irrigated suburban lawn. In this case an isolated patch of moist, cool vegetation loses water at an enhanced rate due to the provision of sensible heat from surrounding dry, hot surfaces. The second is the mesoscale process of advection due to entrainment of drier air down into the daytime planetary boundary layer [McNaughton and Jarvis, 1983]. This may be a common feature over urban areas where strong thermal and mechanical turbulence results in vigorous surface-boundary layer coupling [Hildebrand and Ackerman, 1984].

Acknowledgments. The research was supported by a grant from the Natural Sciences and Engineering Research Council of Canada. Special thanks are due to Dr. and Mrs. J. L. Knox for making their property available and to the Vancouver City Engineering Department for access to the water meter. Field assistance and constructive discussion was generously given by Drs. M. Church, J. Hay, D. Steyn, and a reviewer.

\section{REFERENCES}

Aston, A., Water resources and consumption in Hong Kong, Urban Ecol., 2, 327-353, 1977.

Bell, F. C., The acquisition, consumption and elimination of water by Sydney urban system, Proc. Ecol. Soc. Aust., 7, 160-176, 1972.

Brater, E. F., Steps toward a better understanding of urban runoff processes, Water Resour. Res., 4, 335-347, 1968.

Brutsaert, W., Evaporation in to the Atmosphere: Theory, History and Applications, 299 pp., D. Reidel, Hingham, Mass., 1982.

Campbell, T., La Ciudad de Mexico como ecosistema, Ciencias Urbanas, 1, 28-35, 1982.

Cleugh, H., and T. R. Oke, Suburban-rural energy balance compari- son in summer in Vancouver, B.C., Boundary Layer Meteorol., in press, 1986.

Cohen, S. J. Effects of climatic variations on water withdrawals in metropolitan Toronto, Can. Geogr., 29, 113-122, 1985.

Douglas, I., The Urban Environment, 229 pp., Edward Arnold, London, 1983.

Environment Canada, Atmospheric Environment Service, Monthly Meteorological Summary, January-December 1982, Vancouver International Airport, B.C., 1982.

Environment Canada, Atmospheric Environment Service, Monthly Meteorological Summary, January 1983, Vancouver International Airport, B.C., 1983.

Gardner, W. H., Water content, in Methods of Soil Analysis, Physical and Mineralogical Properties, Mongr. 9, edited by C. A. Black, pp. 92-93, American Society of Agronomy, Madison, Wisc., 1965.

Grimmond, C. S. B., The suburban water balance: Daily, monthly and annual results from Vancouver, M.S. Thesis, 172 pp., Dep. of Geogr., Univ. of B.C., Vancouver, 1983.

Grimmond, C. S. B., T. R. Oke, and D. G. Steyn, Urban water balance, 1, A model for daily totals, Water Resour. Res., this issue.

Hare, F. K., and M. K. Thomas, Climate Canada (2nd ed.), 230 pp., Wiley, Toronto, Ont., 1979.

Hay, J. E., and T. R. Oke, The Climate of Vancouver, 49 pp., Tantalus Research Ltd., Vancouver, B.C., 1976.

Hildebrand, P. H., and B. Ackerman, Urban effects on the convective boundary layer, J. Atmos. Sci., 4I, 76-91, 1984.

Kalanda, B. D., T. R. Oke, and D. L. Spittlehouse, Suburban energy balance estimates for Vancouver, B.C., using the Bowen ratioenergy balance approach, J. Appl. Meteorol., 19, 791-802, 1980.

Landsberg, H. E., The Urban Climate, 275 pp., Academic, Orlando, Fla., 1981.

Lazaro, T. R., Urban Hydrology: A Multidiscipline Perspective, 249 pp., Butterworths, Stoneham, Mass., 1979.

Lindh, G., Urban hydrological modelling and catchment research in Sweden, in Research on Urban Hydrology, edited by B. McPherson, vol. 2, pp. 229-265, UNESCO, Paris, 1978.

L'vovich, M. I., and G. M. Chernogayeva, Transformation of the water balance within the city of Moscow, Sov. Geogr., 18, 302-312, 1977.

McNaughton, K. G., and P. G. Jarvis, Predicting effects of vegetation changes on transpiration and evaporation, Water Deficits Plant Growth, 11, 1-47, 1983.

Oke, T. R., Boundary Layer Climates, 327 pp., Methuen, London, $1978 a$.

Oke, T. R., Surface heat flux and the urban boundary layer, Proceedings WMO Symposium on Boundary-Layer Physics Applied to Specific Problems of Air Pollution, WMO Publ. 510, pp. 63-69, World Meteorol. Org., Geneva, 1978b.

Oke, T. R., Advectively-assisted evapotranspiration from irrigated urban vegetation, Boundary Layer Meteorol., 16, 167-174, 1979.

Oke, T. R., The energetic basis of the urban heat island, $Q . J . R$. Meteorol. Soc., 108, 1-24, 1982.

Oke, T. R., and J. H. McCaughey, Suburban-rural energy balance comparisons for Vancouver B.C.: An extreme case? Boundary Layer Meteorol., 26, 337-354, 1983.

Proctor, S. J., Map Of Vancouver old streams, Water J. Vancouver Aquarium, 3, 4, 1978.

Statistics Canada, Census Division, Census of Canada 1981, Enumeration area data on microfiche, Ottawa, Canada, 1983.

Steyn, D. G., Turbulent diffusion and the daytime mixed layer depth over a coastal city, Ph.D. thesis, 161 pp., Dep. of Geogr., Univ. of B. C., Vancouver, 1980.

Woolmington, E., and J. S. Burgess, Hedonistic water use and lowflow runoff in Australia's national capital, Urban Ecol., 7, 215-227, 1983.

Wright-McLaughlin Engineers Ltd., Urban storm drainage criteria manual, Denver Regional Council of Governments, Denver, Colo., 1969.

Yap, D., Sensible heat fluxes in and near Vancouver, Ph.D. thesis, 177 pp., Dep. of Geogr., Univ. of B. C., Vancouver, 1973.

C. S. B. Grimmond and T. R. Oke, Department of Geography, The University of British Columbia, Vancouver, British Columbia, V6T 1W5, Canada.

(Received October 3, 1985; revised April 22, 1986; accepted May $5,1986$. 